\title{
What an Adult Cardiologist Should Know about Cyanotic Congenital Heart Disease?
}

\section{P. Syamasundar Rao*}

Department of Pediatrics, Division of Pediatric Cardiology, The University of Texas-Houston Medical School/Children's Memorial Hermann Hospital, Houston, TX, USA

\begin{abstract}
The prevalence of congenital heart defects (CHDs) in adults has increased during the last decade such that now there are more adults with CHD than children. Advances in the diagnosis and management of CHD appear to be the reason for such a phenomenon. In this review only cyanotic CHD are addressed. The majority are likely to be those that have undergone corrective or palliative surgery, although rarely uncorrected defects may present in adulthood. Pathophysiologic effects of right to left shunt associated with cyanotic CHD are reviewed. Brief description of the anatomy of the most common cyanotic CHD, namely, tetralogy of Fallot, transposition of the great arteries, truncus arteriosus, total anomalous pulmonary venous connection and tricuspid atresia is presented followed by its management at presentation. The residual defects and their long-term effects along with management strategies for each of the above defects during adulthood are reviewed. Adults who did not have surgical correction in childhood should undergo surgical correction, but they may have a higher risk than seen in children.
\end{abstract}

Keywords: Congenital heart defects; Cyanosis; Surgical correction; Tetralogy of fallot; Transposition of the great arteries; Truncus arteriosus; Total anomalous pulmonary venous connection; Tricuspid atresia; Long-term complications; Adult congenital heart disease

\section{Introduction}

Congenital heart defects (CHDs) may be defined as malformations of the heart or great vessel occurring during intrauterine cardiac development, irrespective of the age at presentation. The incidence is approximately $1 \%$ of live births ( 8 per 1,000$)$. The etiology is largely unknown and the majority can be explained by multifactorial inheritance hypothesis [1]. Advances in perinatal cardiac care, noninvasive and invasive diagnosis, anesthesia, surgical and transcatheter therapeutic techniques and post-operative care increased survival rates such that $85 \%$ to $90 \%$ of babies born with CHD reach adulthood [2]. It appears that there are more people over the age of 20 with CHD than infants, children and adolescents put together. The population of adult $\mathrm{CHD}$ patients is growing at a rate of $5 \%$ per year, with more than one million adult CHD patients in the US. One-third of these are complex $\mathrm{CHD}$, a third are moderately severe defects and the final third, simple CHD.

The most of the cyanotic CHDs presenting in adulthood are likely be those that have undergone palliative or corrective surgery in childhood. Less frequently, previously un-operated patients may present during adult life either because of late detection or due to minimal symptomatology secondary to balanced circulation with a large inter-ventricular communication (or single ventricle) and moderate degree of pulmonary stenosis.

In this review I will address "what the practicing cardiologist should know about cyanotic CHD"; acyanotic CHD will not be discussed because of limitations of the space. This review will attempt to address cyanotic CHDs that are likely to present in adulthood, explore treatment options for these heart defects and discuss the role of endovascular interventions, as applicable. First a brief review of general aspects of cyanotic CHD will presented. Then the most important of the cyanotic CHDs, the so called " 5 Ts", namely, tetralogy of Fallot, transposition of the great arteries, truncus arteriosus, total anomalous pulmonary venous connection and tricuspid atresia, will be reviewed. Other lesions such as pulmonary atresia with intact ventricular septum and hypoplastic left heart syndrome may also present as adults and most of them might have had Fontan surgery earlier in life and the discussion of these has been include under section on "Tricuspid atresia and other single ventricle defects". Other cyanotic CHD lesions that may present in adulthood such as Ebstein's anomaly of the tricuspid valve, double-outlet right ventricle and others will not be reviewed.

\section{General Aspects of Cyanotic CHD}

Patients who have not been corrected or palliated by aortopulmonary shunts are likely to be cyanotic because of intra-cardiac right-to-left shunting. The causes of right-to-left shunt are obstruction to pulmonary blood flow (for example tetralogy of Fallot), complete admixture of pulmonary and systemic venous returns (for example, total anomalous pulmonary venous return and double-inlet left ventricle) and parallel rather than in-series circulation (for example, transposition of the great arteries). Right-to-left shunt produces arterial desaturation and cyanosis. Clubbing or hypertrophic osteoarthropathy usually develops after six to 12 months of cyanosis and is manifested by thickening and widening of ends of the fingers and toes with convex nails. The reduced arterial oxygen saturation stimulates the production erythropoietin from the kidney, which in turn stimulates the bone marrow to produce more red blood cells, causing polycythemia. This is a compensatory mechanism to increase the oxygen carrying capacity in patients with significant arterial desaturation. While polycythemia is helpful, when hematocrit exceeds $70 \%$, it becomes counter-productive because it produces hypervolemia, causes increased yield shear stress and high blood viscosity which in turn increases peripheral vascular resistance, reduces cardiac output and decreases oxygen delivery

*Corresponding author: Rao PS, MD, Professor and Emeritus Chief of Pediatric Cardiology, Department of Pediatrics, Division of Pediatric Cardiology, University of Texas-Houston Medical School, 6410 Fannin Street, UTPB Suite \# 425. Houston, TX 77030, USA, Tel: 713-500-5738; Fax: 713-500-5751; E-mail: p.syamasundar. Rao@uth.tmc.edu

Received March 13, 2013; Accepted March 15, 2013; Published March 22, 2013

Citation: Rao PS (2013) What an Adult Cardiologist Should Know about Cyanotic Congenital Heart Disease? J Cardiovasc Dis Diagn 1: 104. doi:10.4172/23299517.1000104

Copyright: (c) 2013 Rao PS. This is an open-access article distributed under the terms of the Creative Commons Attribution License, which permits unrestricted use, distribution, and reproduction in any medium, provided the original author and source are credited. 
to the tissues. Symptoms of polycythemia, namely, headache, chest pain, fatigue, muscle cramps or irritability develop. In addition, high hematocrit increases the risk of cerebro-vascular accidents. Polycythemia should be treated by erythropheresis instead of instead of phlebotomy. Some patients may develop iron deficiency and should receive oral iron therapy. Cyanotic CHD patients with significant arterial desaturation and polycythemia tend to have coagulation problems; it is likely that these abnormalities are related decreased plasma volume. Patients with low oxygen saturation (60\% or less) and high hematocrit should be screened for prothrombin time, partial thromboplastin time and platelet count prior to any cardiac or noncardiac surgery, including dental extractions. Most of the coagulation abnormalities can be reversed by erythropheresis mentioned above, and should be performed prior to cardiac or non-cardiac surgery, cardiac catheterization and catheter interventions. Other problems associated with polycythemia are hyperuricemia, gout and uric acid nephropathy and therefore, serum uric level should be monitored in adults with cyanotic CHD. Finally these patients with intra-cardiac right-to-left shunting are candidates for developing brain abscess, cerebro-vascular accidents (CVAs) and transient ischemic attacks (TIAs) presumably secondary to paradoxical embolism because of right to left shunt (by bypassing the pulmonary filtering mechanism).

Adult patients with cyanotic CHD, whether corrected or palliated should be allowed participate in activities as tolerated, receive subacute bacterial endocarditis (SBE) prophylaxis prior to any oro-dental or genito-urinary procedures or surgery that are likely to produce bacteremia and receive routine immunizations, as seen fit by the primary care physician.

\section{Tetralogy of Fallot}

Tetralogy of Fallot (TOF) is defined as a constellation of four abnormalities to include ventricular septal defect (VSD), pulmonary stenosis (PS), right ventricular (RV) hypertrophy and dextroposition of the aorta. Total surgical correction to include closure of VSD and resection of the infundibulum and/or relief of pulmonary valvar obstruction is usually performed in infancy with very little mortality. When total correction is not feasible in the neonatal period or infancy (for example, pulmonary atresia, pulmonary arterial (and/or annular) hypoplasia, "smallish" left ventricle, and/or anomalous course of a major coronary artery in the right ventricular infundibulum), palliative surgery to augment pulmonary blood flow by a classic or modified Blalock-Taussig shunt is recommended; most surgeons prefer modified Blalock-Taussig shunt using an interposition Gore-Tex graft between right or left subclavian (or brachio-cephalic) arteries to the ipsilateral pulmonary artery $[3,4]$. Then, total surgical correction is performed later in childhood. Some variants of TOF (pulmonary atresia, multiple aorto-pulmonary collateral arteries (MAPCAs), absent pulmonary valve syndrome) may require right ventricle to pulmonary artery valved conduit (usually a homograft) at the time of repair.

While it is rare for an un-operated TOF patient to present in adulthood, particularly in the developed countries, residual defects and long-term complications can and do occur, bringing them to medical attention. These include residual shunts, arrhythmias, residual RV outflow tract and branch pulmonary artery obstruction, pulmonary insufficiency, dilated aortic root and aortic insufficiency.

\section{Residual shunts}

Residual VSDs, if present are usually small, tend to close spontaneously and rarely require repeat surgery. Atrial septal defects (ASDs) or patent foramen ovale (PFO) are usually closed at the time of total correction of TOF. However, some surgeons do not close these defects in order to allow right to left shunt to maintain cardiac output in the immediate post-operative period. If such an atrial defect causes significant left to right shunt in adolescence or adulthood, transcatheter and rarely surgical closure may become necessary $[5,6]$.

\section{Arrhythmias}

Ventricular tachycardia and sudden death have been observed in several follow-up studies [7-10]. The prevalence of sudden death is estimated to be $0.27 \%$ during the first 25 years after surgery and increases to $0.94 \%$ after 25 years [11]. The risk factors for sudden death are sustained ventricular tachycardia, pulmonary insufficiency, QRS duration $>180 \mathrm{~ms}$ and left ventricular dysfunction [10]. Non-invasive studies (Echo, MRI) and ambulatory ECG (Holter and event recorders) monitoring to detect the abnormalities and address them when found is recommended. Invasive electrophysiological studies may be warranted in symptomatic and high risk patients [12]. Other arrhythmias such as heart block, sinus node dysfunction, atrial fibrillation/flutter and supraventricular tachycardia may be seen, but with lesser frequency [13].

\section{Branch pulmonary artery stenosis}

Branch pulmonary artery stenosis may develop in some patients and it may be related to inadequately addressing the stenosis at the time of surgical repair or due to distortion related prior shunt procedures. The indications for intervention are not well defined but we recommend intervention if the proximal pulmonary artery/right ventricular systolic pressures are in excess of half systemic pressure in the presence of bilateral stenosis. In cases with unilateral stenosis, the peak-to-peak pressure gradients are not useful in determining the degree of obstruction. Narrowing demonstrated by angiography or other imaging studies such CT or MRI and quantitative pulmonary perfusion scans with less the $30 \%$ flow distribution to the ipsilateral lung are good indications for intervention. Relief of the stenosis is particularly useful in patients that also have pulmonary regurgitation. Balloon angioplasty may be of value in discrete obstructions. Long segment stenoses should be treated with stents and an example is shown in figure $1[14,15]$. For lesions not amenable to trans-catheter intervention, surgical therapy with patch angioplasty maybe required.

\section{Right Ventricular (RV) outflow tract obstruction}

Residual RV outflow tract obstruction may develop at the infundibular, valvar or supravalvar pulmonary artery level. Indications for intervention are RV systolic pressure more than half systemic pressure. Residual infundibular (subpulmonary) and supravalvar pulmonary artery stenosis require surgical intervention. Valvar stenosis may be adequately addressed by balloon pulmonary valvuloplasty [16]

\section{Right ventricle to pulmonary artery conduit stenosis}

As mentioned above, some variants of TOF require right ventricle to pulmonary artery valved conduit (usually a homograft) at the time of initial repair. Calcific degeneration and development of obstruction of bioprosthetic right ventricular-to-pulmonary artery conduits does occur frequently. The indication for intervention, again is elevated right ventricular systolic pressure $>50 \%$ of left ventricular systolic pressure. Balloon dilation of these valves has produced some improvement with nominal extension of the life span of the conduit [17]. However, stents (Figure 2) may be more effective in extending the life of the conduit $[15,18]$. More recently, trans-catheter delivered pulmonary valve replacement has been used and is under active investigation [19-22]. 
Citation: Rao PS (2013) What an Adult Cardiologist Should Know about Cyanotic Congenital Heart Disease? J Cardiovasc Dis Diagn 1: 104. doi:10.4172/2329-9517.1000104

Page 3 of 9

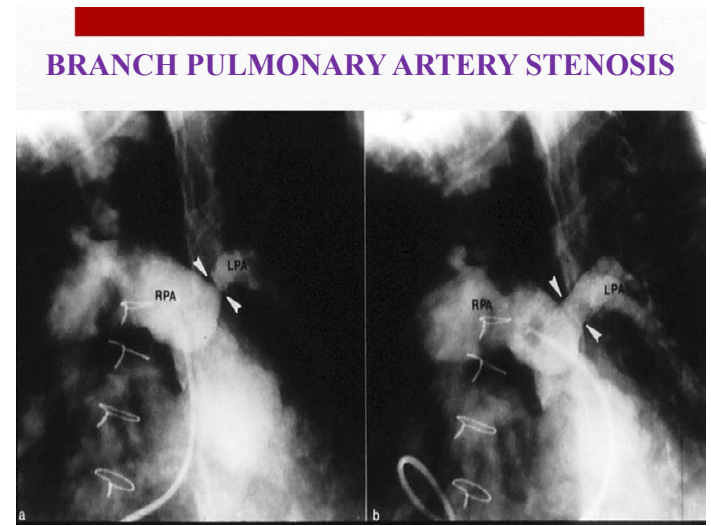

Figure 1: Selected cineangiographic frames from main pulmonary artery injection in a sitting-up view demonstrating an enlarged right pulmonary artery (RPA) and small and markedly narrowed (arrowheads) left pulmonary artery (LPA) prior to (a) and following (b) stent (arrowheads) implantation in a patient who had surgical correction of several years previously.

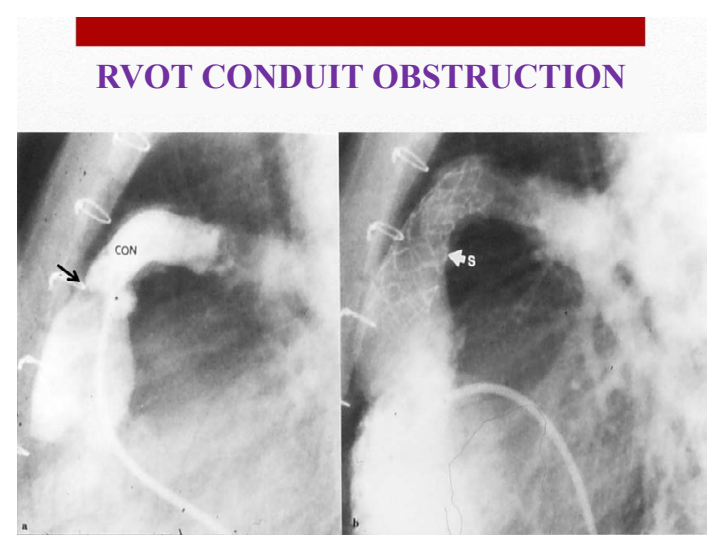

Figure 2: Selected cineangiographic frame from right ventricular outflow injection in lateral view demonstrating narrowed (arrow) conduit (CON) with a pressure gradient of $60 \mathrm{mmHg}(\mathrm{a})$. Following stent (S) implantation (b), there was free forward flow with reduction of the pressure gradient to less than 10 $\mathrm{mmHg}$.

\section{Dilated aortic root and aortic insufficiency}

Enlarged aortic root with mild aortic insufficiency is common in TOF and usually requires no intervention. In some studies, structural abnormalities of the aortic wall have been observed. Dissection and aneurysmal dilatation are extremely rare but have been reported $[23,24]$.

\section{Pulmonary insufficiency}

Since the pulmonary valve is abnormal, pulmonary insufficiency is present in all most all patients. This is more so in patients that had trans-annular patch. Over time, progressive dilatation of the right ventricle ensues. Follow-up of these patients to monitor RV size and function is necessary. MRI is probably most useful in this regard. RV end-diastolic volume $>160 \mathrm{ml} / \mathrm{m}^{2}$ is generally considered an indication for treatment. The valve should be replaced prior to deterioration of RV function. Surgical or transcatheter valve replacements are available options. In some patients, replacement of the pulmonary valve with a homograft or bio-prosthetic valve becomes necessary in childhood. These replaced pulmonary valves deteriorate causing stenosis and/or regurgitation and may require re-replacement. Use of trans-catheter delivered pulmonary valves, as mentioned above, is under investigation and may become available for routine use in the near future.

\section{Transposition of the Great Arteries}

In transposition of the great arteries (TGA), the most common $\mathrm{CHD}$ in the neonate, the aorta arises from the morphologic right ventricle and the pulmonary artery from the morphologic left ventricle. In the most common form, referred to as complete transposition, the atria are normal in position (atrial situs solitus), there is atrioventricular concordance (right atrium connected to the right ventricle and the left atrium to the left ventricle), $d$ loop of the ventricles (right ventricle is on the right and left ventricle on the left), ventriculo-arterial discordance (aorta arising from the right ventricle and the pulmonary artery from the left ventricle) and the aortic valve is located to the right of pulmonary valve (d-TGA). Three types of TGA are recognized [25]. TGA with intact ventricular septum, TGA with VSD and TGA with VSD and PS. For babies with intact ventricular septum as well as those with VSD, the treatment initially was physiological correction by atrial switch procedures but the more recent preference is anatomic correction by arterial switch procedure [26-29]. However, babies with TGA, VSD and PS are approached with Rastelli operation [30,31].

It is extremely rare for an un-operated TGA patient to present in adulthood. Long-term complications and residual defects following infant and childhood surgery do occur and these depend upon the type surgery that these children have had at presentation.

\section{Atrial switch operation}

The babies that underwent atrial (venous) switch (Senning [26] and Mustard et al. [27]) procedures in 1960s thru' 1980s have reached adulthood and many of these patients have been reported to develop complications and these include arrhythmias, baffle obstructions, baffle leaks, tricuspid insufficiency and RV dysfunction.

Arrhythmias: Bradycardia (sinus node dysfunction) and supraventricular tachycardia, mostly related to atrial surgery occur frequently; there is decreasing prevalence of sinus rhythm with increasing time from surgery $[32,33]$. These arrhythmias should be addressed with anti-arrhythmic medications, radiofrequency ablation, pacemakers and ICD, as deemed appropriate in collaboration with electrophysiologists familiar with arrhythmias associated with CHD. There is higher incidence of sudden death; the risk factors are not known, but are likely to be arrhythmias $[9,34]$.

Baffle obstructions: Baffle obstruction may develop in 10\% patients [33]. Systemic venous obstruction is more common than pulmonary venous obstruction and superior vena caval (SVC) obstruction is more frequent than inferior vena caval stenosis [35]. Symptoms such as upper body edema indicative of SVC syndrome are rare and are usually detected by echo-Doppler studies, angiography or MRI performed either during routine follow-up or prior to considering placing pacemaker wires. Balloon angioplasty of stenosed baffle obstruction (Figures 3 and 4) is often successful; however long-segment obstructions would require stents (Figure 5) [14,15,35,36].

Baffle leaks: Baffle leaks are usually small and not hemodynamically significant and are best detected by selective vena caval cineangiography. Indication for intervention are significant left to right shunt (Qp:Qs $>1.5: 1$ ), right to left shunt and transvenous pacemaker wires. Transcatheter device closure is preferable to surgical closure [37].

Tricuspid insufficiency and RV dysfunction: In the Senning and Mustard procedures, the right ventricle remains the systemic ventricle 
Citation: Rao PS (2013) What an Adult Cardiologist Should Know about Cyanotic Congenital Heart Disease? J Cardiovasc Dis Diagn 1: 104. doi:10.4172/2329-9517.1000104

Page 4 of 9

TRANSPOSITION OF THE GREAT ARTERIES

Post-Mustard - Superior Baffle Obstruction - Balloon PRE

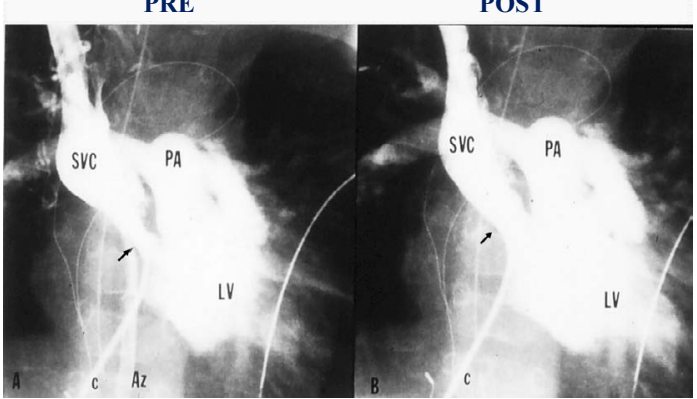

Figure 3: Selected cineangiographic frame from superior vena cava (SVC) injection in posterio-anterior view demonstrating stenosis (arrow) of the SVC baffle $(A-P R E)$ in a patient who had Mustard procedure in the past. Following balloon angioplasty ( $\mathrm{B}$ - POST), the narrowed segment improved (arrow). The azygos vein $(A z)$ seen in $A$ is no longer seen in $B$, presumably related relief of SVC obstruction following balloon angioplasty. C, catheter; LV left ventricle; PA, pulmonary artery.

TRANSPOSITION OF THE GREAT ARTERIES

Post-Mustard - Inferior Baffle Obstruction - Balloon PRE POST

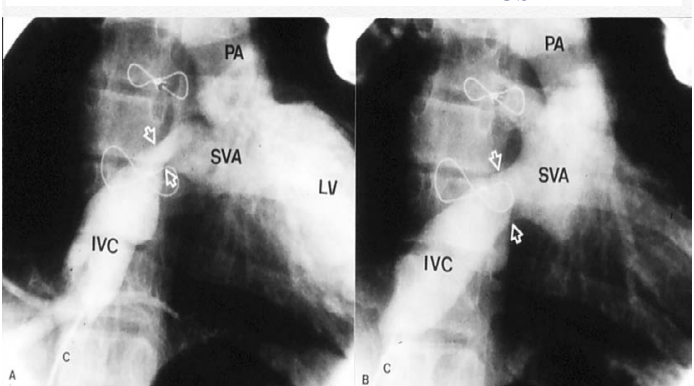

Figure 4: Selected cineangiographic frame from inferior vena cava (IVC) injection in right anterior oblique view demonstrating stenosis (arrows) of the IVC baffle (A - PRE) in a patient who had Mustard procedure several years previously. Following balloon angioplasty (B - POST), the narrowed segment improved (arrows). C, catheter; LV left ventricle; PA, pulmonary artery; SVA, systemic venous atrium.

and is allowed to pump against the systemic circuit. RV dysfunction with or without tricuspid insufficiency may develop in $15 \%$ of patients in their second and third decades of life $[33,38]$. At first, treatment with the usual anti-congestive therapy with angiotensin-converting enzyme (ACE) inhibitors for afterload reduction may be initiated. Severe tricuspid insufficiency may be addressed with tricuspid valve repair or replacement if the RV function is reasonably preserved. In cases with severe failure, double switch operation with retraining the left ventricle and heart transplant are available options.

\section{Arterial switch operation}

The babies that underwent arterial switch (Jatene [29]) procedures in 1980s and 1990s are just reaching adulthood. Vast majority of patients (>95\%) remain asymptomatic 25 years after surgery [39]. Residual supravalvar aortic stenosis, supravalvar pulmonary artery stenosis and branch pulmonary artery stenosis may be seen; when these are severe, transcatheter (balloon angioplasty or stent) or surgical therapy may become necessary. Neoaortic dilatation with aortic insufficiency may be seen, but severe insufficiency is seen in less than $1 \%$ of the patients. Coronary artery problems can occur and were seen in $7 \%$ of patients undergoing selective coronary angiography $[40,41]$.

\section{Rastelli operation}

As reviewed in the Right Ventricle to Pulmonary Artery Conduit Stenosis section of TOF, calcific degeneration and development of obstruction of bioprosthetic right ventricular-to-pulmonary artery conduits do occur and the management is similar to that described in that section. Conduit valve insufficiency may also develop. Restriction at the VSD level causing sub-aortic obstruction can also develop in some patients and when severe, surgical intervention is necessary.

\section{Truncus Arteriosus}

Truncus arteriosus is a rare cyanotic heart defect and is characterized by a common arterial trunk (truncus) originating from base of the heart; the truncus gives rise to the aorta, pulmonary artery and coronary arteries [42]. A large VSD is present in the conal septum. It is classified largely based on the origin and distribution of the pulmonary arteries. These patients are usually operated in the first few weeks of life; surgery consists of closure of VSD, separation of the pulmonary arteries from the truncus and connecting them to right ventricle via a valved conduit, usually a homograft and closure of the defect in the truncus created by disconnecting the pulmonary artery/ arteries [43].

Again it is rare for an un-operated truncus patient to present in adulthood. Development of branch pulmonary artery stenosis and RV-PA conduit obstruction, requiring transcatheter and/or surgical intervention in more than half of the patients during childhood has been noted [44]. These obstructive lesions may persist into adulthood and may require additional interventions. Issues related to right ventricle to pulmonary artery conduit stenosis have been detailed in the preceding sections on TOF and TGA. Dilatation of the neoaorta (old truncus) occurs in most of the patients during follow-up; the Z-score was $5.1 \pm 2.3$. However, no dissection or rupture occurred. In the presence of neoaortic valve regurgitation and left ventricular dilatation, root replacement surgery may be required [45].

\section{Total Anomalous Pulmonary Venous Connection}

In this entity, all the pulmonary veins drain into a common

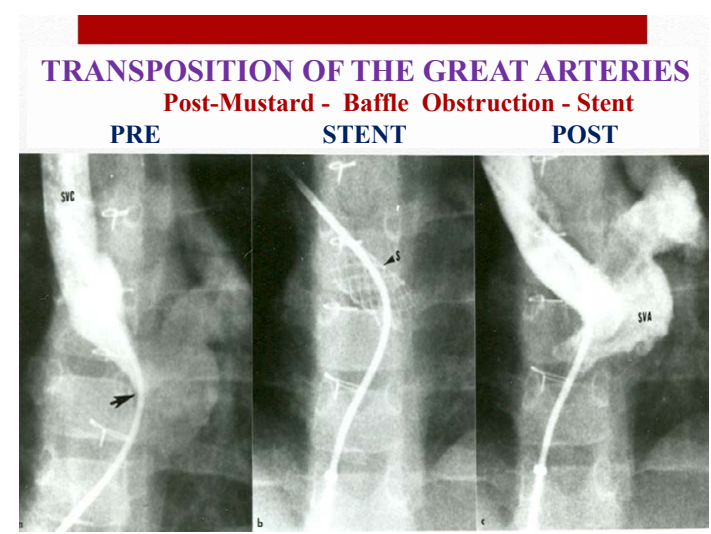

Figure 5: Selected cineangiographic frame from superior vena cava (SVC) injection in posterio-anterior view demonstrating severe, long segment stenosis (arrow) of the SVC baffle (a - PRE) in a patient who had Mustard procedure in the past. Following stent (arrow) implantation (b-STENT), the narrowed segment improved (c - POST). SVA, systemic venous atrium. 
pulmonary vein which is then connected to the left innominate vein, superior vena cava, coronary sinus, portal vein or other rare sites. Occasionally individual veins drain directly into the right atrium. The TAPVC is classified based on the anatomic location to which the connecting veins drain and whether the pulmonary venous return is obstructed. Irrespective of the type, surgical correction is by anastomosis of the common pulmonary vein with the left atrium in the neonatal period or infancy is mandatory. Follow-up after surgery to detect development of obstruction at the site of anastomosis of the common pulmonary vein with the left atrium and pulmonary venous obstruction is generally recommended.

It is unlikely that TAPVC babies will survive to the adult age without surgical correction. However, some patients may present in adolescence and adulthood presumably related to mild obstruction of the pulmonary venous return [46-51]. Exercise intolerance, mild cyanosis and heart failure are usually the presenting symptoms [51]. Clinical findings are those seen with ASD. Echocardiography and other imaging studies (CT or MRI) may be required for diagnosis. Surgical correction is by anastomosis of the common pulmonary vein with the left atrium, similar to that done in neonates. Arrhythmias and tricuspid insufficiency are more common than in infants [46-51].

\section{Tricuspid Atresia and Other Single Ventricle Defects}

Tricuspid atresia is defined as congenital absence or agenesis of the morphologic tricuspid valve; the most common muscular type of tricuspid atresia is characterized by a dimple or a localized fibrous thickening in the floor of the right atrium and is most commonly classified based on associate defects, namely, relationship of great arteries and status of pulmonary arteries (atresia, stenosis or normal) [52,53]. The VSD may be large, small or non-existent. When present, the VSD is most commonly located in the muscular septum and the majority of the VSDs is restrictive and produces sub-pulmonary stenosis in patients with normally related great arteries and subaortic stenosis in patients with transposition of the great arteries [54-57]. Essentially there is only one functioning ventricle in this lesion. There are many other cyanotic CHDs that have one functional ventricle and these include double-inlet left ventricle (single ventricle), pulmonary atresia with intact ventricular septum with RV hypoplasia, hypoplastic left heart syndrome, unbalanced common atrioventricular canal and any other complex CHD with hypoplasia of one of the ventricles.

These babies require palliative surgery/management at presentation, usually in the neonatal period, followed by "corrective" surgery later. Since there is only one functioning ventricle, this ventricle is used to pump into the systemic arterial circuit and divert the systemic venous return into the pulmonary arteries without the use of the ventricle. This is performed by Fontan/Kreutzer procedure $[58,59]$. However, this can't be performed in the neonate and young infant because of high pulmonary artery pressure/resistance and therefore, it is addressed by multistage surgery. Since the original description, this surgery has undergone a number of modifications and the current approach is staged total cavopulmonary connection (TCPC) [60].

Stage I: At presentation, modified Blalock-Taussig shunt is performed for babies with pulmonary oligemia and banding of the pulmonary artery is done for babies with increased pulmonary flow [4]. If there is adequate pulmonary flow, no intervention would be necessary at presentation. In babies with hypoplastic left heart syndrome, Norwood procedure with either a modified Blalock-Taussig or Sano shunt is undertaken. Stage II $[61,62]$ : At about the age of six months bi-directional Glenn procedure is performed by anastomosis of the superior vena cava to pulmonary artery, end to side. Previously created shunts are closed. If there are any other defects, these are corrected at the same time. Stage III. One year later diversion of IVC blood into the pulmonary arteries is carried out. This is most commonly performed with an extra-cardiac conduit. Most surgeons create a 4 to $6 \mathrm{~mm}$ size fenestration between the conduit and the atrial mass in all most all patients; the fenestration is closed by transcatheter methodology six to twelve months later.

Presentation as adults with any of these complex defects is uncommon. Many patients who had the classic Fontan (atriopulmonary connection) have reached adulthood and patients who had TCPC are just reaching adulthood. It appears that the complications during follow-up are more frequent with classic Fontan than with TCPC. The identified problems are discussed below.

\section{Arrhythmias}

The arrhythmias are particularly common with atrio-pulmonary connections (classic Fontan); these are mostly atrial arrhythmia (atrial flutter/fibrillation and supraventricular tachycardia) and may be related to macro re-entry circuits. Initial management is with anti-arrhythmic medications, although this is with variable success. Complete hemodynamic and angiographic evaluation should be undertaken and if obstructive lesions are found in the Fontan circuit, they should be treated with balloon angioplasty, stent or even surgery, as deemed appropriate, to relieve the obstruction. Radiofrequency ablation is the next step; the success rate is in the order of $80 \%$ [63]. However, recurrence rate is high (30 to $40 \%$ ) for resistant arrhythmias, Fontan revision with debulking of the atrial mass, conversion to TCPC and Maize procedure may become necessary $[63,64]$. In some patients atrioventricular block and sick sinus syndrome may be develop; pacemaker insertion may become necessary in such patients. Ventricular arrhythmias are less frequent.

\section{Obstructed Fontan pathways}

Obstructive lesions may develop at the SVC or inferior vena cava (IVC) levels, but are less frequent than branch pulmonary artery stenosis. Prompt investigation of any signs and symptoms suggestive of obstruction in the Fontan circuit is mandatory. Because of poor echo windows MRI and magnetic resonance angiography (MRA) may be needed to define these obstructions. Cardiac catheterization and angiography may be needed to confirm or exclude such obstruction. If significant obstruction is found, balloon angioplasty, stent placement (Figure 6), and, if necessary, surgery should be undertaken to provide prompt relief.

\section{Cyanosis and cerebrovascular accidents}

Intentional Fontan fenestrations, residual atrial defects and defects between the lateral tunnel or extracardiac conduit and the atrial mass cause right to left shunt because of higher right side pressures. This may cause significant arterial hypoxemia and cyanosis. In addition, these may become sites for paradoxical embolism causing TIAs and CVAs as well as other systemic emboli. Transcatheter occlusion (Figure 7) of the fenestrations and atrial defects with conventional atrial septal closing devices is recommended. Test occlusion of the fenestration should be done to ensure that adequate cardiac output is maintained after closure. Some surgeons place tubular fenestrations and these may require coils, Amplatzer vascular plug (AGA Medical, Golden Valley, Minnesota) (Figure 8) or other devices. Late follow-up results after fenestration closure appear encouraging [65]. 
Citation: Rao PS (2013) What an Adult Cardiologist Should Know about Cyanotic Congenital Heart Disease? J Cardiovasc Dis Diagn 1: 104. doi:10.4172/2329-9517.1000104

Page 6 of 9

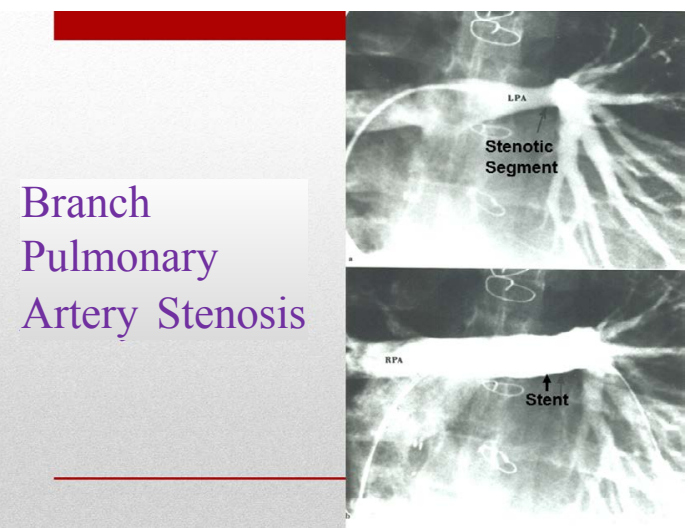

Figure 6: Selected cineangiographic frames from the pulmonary artery injection in posterio-anterior view demonstrating normal right pulmonary artery (RPA) and narrowed (arrow) left pulmonary artery (LPA) prior to (a) and following (b) stent (arrow) implantation in a patient who had Fontan operation several years previously.

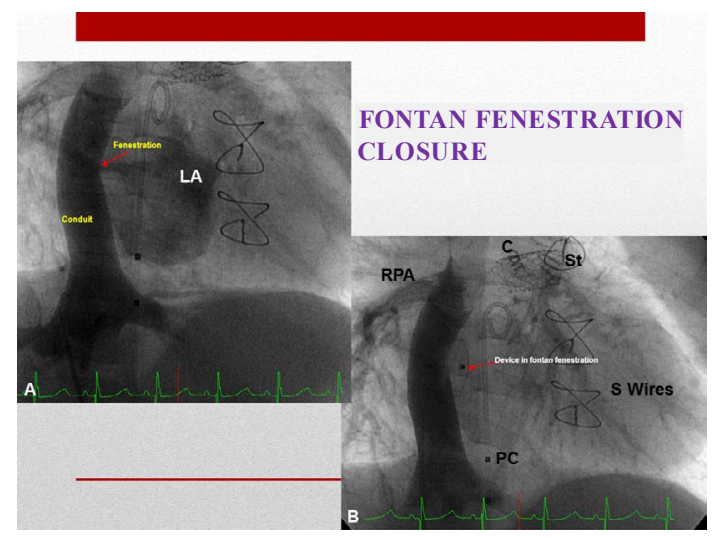

Figure 7: A. Selected cineangiographic frame from conduit injection in posterio-anterior view demonstrating fenestration opacifying the left atrium (LA). B. Following closure of the fenestration with an Amplatzer Septal Occluder (red arrow), the fenestration shunt is no longer seen. The arterial oxygen saturations improved from high 80 s to high 90 s. C, coil previously placed to occlude aortopulmonary collateral vessel; PG, pigtail catheter; RPA, right pulmonary artery, $\mathrm{S}$, stent previously placed to relieve left pulmonary artery obstruction; $\mathrm{S}$ wires, sternal wires.

\section{Thrombus formation}

There is tendency for thrombus formation in the Fontan circuit, presumably related to slow flow; the prevalence is as high as 15 to $30 \%[66,67]$. The thrombi may not be detected by conventional transthoracic echocardiograph, but may detected transesophageal echocardiography, VQ scans or CT angiography. Because of this reason thromboprohylaxis is generally recommended. Of the two methods used, namely warfarin and aspirin, no difference for risk of thrombosis between these regimens was found [68]. Based similar, but uncontrolled studies in the past, most pediatric cardiologists use aspirin for thromboprohylaxis in children. Perhaps more potent drugs such as clopidogrel (Plavix) may be used in adults.

\section{Development of collateral vessels}

Some patients may develop systemic arterial to pulmonary arterial or systemic venous to pulmonary venous (Figures 9 and 10) collateral vessels. Systemic to pulmonary arterial collateral vessels cause left ventricular volume load while systemic venous to pulmonary venous collateral vessels arterial hypoxemia and form potential sites for paradoxical embolism. These should be occluded with coils or vascular plugs (Figures 9 and 10).

\section{Protein losing enteropathy}

In protein-losing enteropathy (PLE) loss of protein in the bowel, secondary to lymphatic distension may be due to elevated systemic venous pressure, although this has been seen in patients with normal Fontan pressures. PLE manifests with diarrhea, edema, ascites, and/or pleural effusions. Serum hypoalbuminemia and elevated stool alpha-1antitrypsin levels are suggestive of the diagnosis. PLE may be confirmed with technetium 99m-labeled human serum albumin scintigraphy [69]. The etiology of PLE is not known. The prevalence of PLE appears to be lower $(1.2 \%)$ in the TCPC group than in atriopulmonary connection patients (11.1\%) [70-72].

Because of high mortality rate with PLE, rapid and aggressive management is highly recommended. Initial supportive treatment

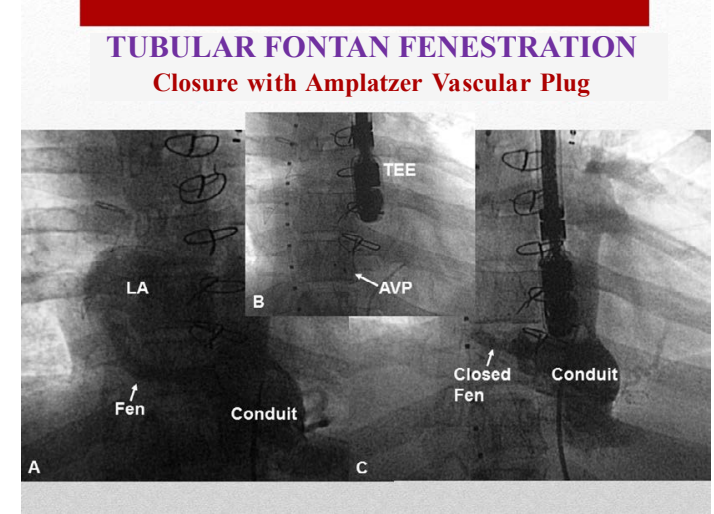

Figure 8: A. Selected cineangiographic frame from conduit injection in posterio-anterior view demonstrating tubular fenestration (Fen) opacifying the left atrium (LA). B. The fenestration is occluded with an Amplatzer vascular plug (arrow -AVP). C. Repeat conduit injection following closure of the fenestration with an AVP (arrow); the fenestration shunt is no longer seen. The arterial oxygen saturations improved. TEE (transesophageal echocardiography) probe is seen $B$ and $C$.

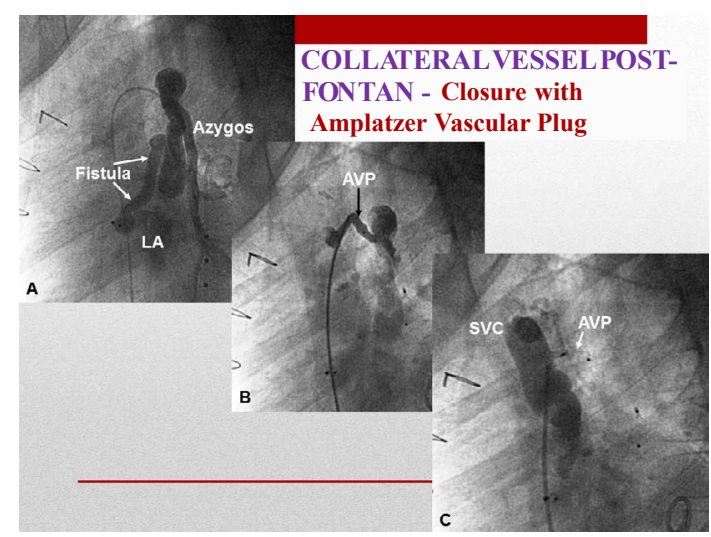

Figure 9: A. Selected cineangiographic frame in lateral view with the catheter positioned at the superior vena cava (SVC)/azygos junction demonstrating a fistula which results in opacification of the left atrium (LA). B. The fistula is occluded with an Amplatzer vascular plug (arrow -AVP) with some residual flow. C. Repeat SVC injection shows complete occlusion by the AVP. 


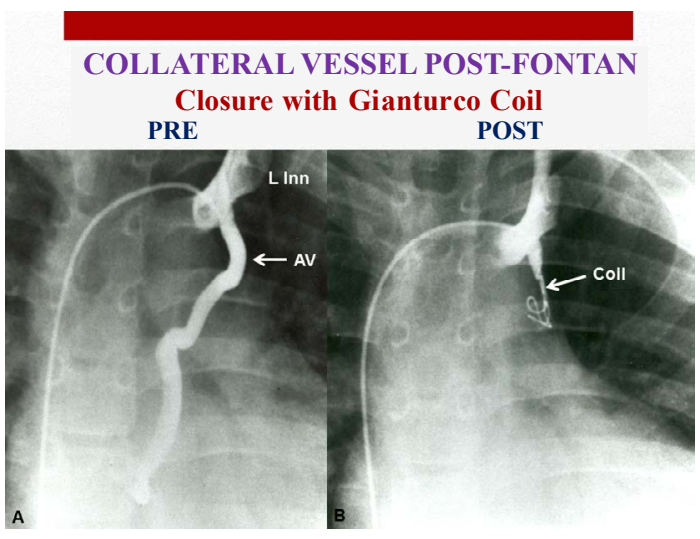

Figure 10: A (PRE). Selected cineangiographic frame from left innominate vein ( $\mathrm{L} \mathrm{Inn}$ ) injection in posterio-anterior view demonstrating an anomalous vein (AV) opacifying the atrial mass. B (POST). Following closure with Gianturco coil (arrow) the AV is completely occluded and the systemic arterial saturation improved.

consists of medium-chain triglycerides diet, parental albumin administration and perhaps, replacement of immunoglobulins. Obstruction in the Fontan pathway must be scrutinized and, if found, relieved by means of transcatheter or surgical therapy. Similarly, aortopulmonary connections [73] and naturally occurring or prior surgical shunts should be searched for and occluded with transcatheter or surgical methodology, as deemed fit. Treatment with prednisone, elementary diet, calcium replacement, regular high-molecular-weight heparin and low-molecular-weight heparin, somatostatin, highdose spironolactone, sildenafil, and resection of localized intestinal lymphangiectasia (if demonstrated), as reviewed elsewhere have been advocated with variable success [72].

A number of approaches such as reduction of right atrial pressure by creating an ASD, conversion of atriopulmonary type of Fontan to total cavopulmonary connection, atrioventricular sequential pacing and transplantation have been attempted, some with success [74-80].

In an any of the above scenarios with so called "failed Fontan," after excluding or treating obstructive lesions and residual shunts, consideration for atrioventricular sequential pacing, conversion of atrioventricular Fontan to total cavopulmonary anastomosis and cardiac transplantation should be given [64,78-83].

\section{Surgical Correction in Adulthood}

As mentioned earlier, though rare, un-corrected and palliated cyanotic CHD patients may present during adult life either because of late detection or due to minimal symptomatology secondary to balanced circulation. Surgical correction should be performed in a manner similar to that is described for children, but with the understanding that there is a higher risk for surgery because of abnormalities of myocardial function and elevated pulmonary artery pressure/resistance.

\section{Summary and Conclusions}

Because of advances in the diagnosis and management of CHD, many of them are reaching adulthood such that the number of adults with CHD exceeds that in children at the present time and consequently, there are more than one million adults with $\mathrm{CHD}$ in USA alone. This review focuses on cyanotic CHD. Patients with uncorrected and palliated cyanotic CHD have intra-cardiac right to left shunt with resultant arterial desaturation, cyanosis, clubbing and polycythemia. The latter may in turn cause coagulation abnormalities and symptomatic polycythemia. Other attendant problems are hyperuricemia, gout and uric acid nephropathy. Patients with intracardiac right-to-left shunting may also develop brain abscess, CVAs and TIAs, presumably secondary to paradoxical embolism.

Patients who had surgical "correction" may have residual defects and abnormalities which may become significant with time. The most common cyanotic CHDs, the so called 5Ts, namely, tetralogy of Fallot, transposition of the great arteries, truncus arteriosus, total anomalous pulmonary venous connection and tricuspid atresia were discussed in this review. Long-term issues with TOF patient are residual shunts, arrhythmias, residual RV outflow tract and branch pulmonary artery obstruction, pulmonary insufficiency, dilated aortic root and aortic insufficiency. Long-term problems with transposition of the great arteries depend upon the type of surgical correction they had. Patients who had atrial or venous switch (Senning and Mustard) procedures may develop arrhythmias, baffle obstructions, baffle leaks, tricuspid insufficiency and RV dysfunction while those that had arterial switch (Jatene) procedures may have supravalvar aortic stenosis, supravalvar pulmonary artery stenosis and branch pulmonary artery stenosis, neoaortic dilatation with aortic insufficiency and coronary artery obstruction. Patients who had Rastelli operation may manifest calcific degeneration of the conduit and valve and develop obstruction of bioprosthetic right ventricular-to-pulmonary artery conduits. Similarly patients with truncus arteriosus may develop conduit obstruction and in addition they may develop branch pulmonary artery stenosis, dilatation of the neoaorta (old truncus) and neoaortic valve regurgitation. Patients who had correction of total anomalous pulmonary venous connection may develop obstruction at the site of anastomosis of the common pulmonary vein with the left atrium and pulmonary venous obstruction. Patients who had Fontan correction of tricuspid atresia and other single ventricle defects may develop arrhythmias, obstructed Fontan pathways, cyanosis and CVAs, thrombus formation, collateral vessels and protein loosing enteropathy. Diagnosis and management concepts for each of the above are briefly reviewed. Patients who had not previously been corrected may undergo surgical correction, but with higher morbidity and mortality than that seen in childhood.

\section{References}

1. Nora JJ (1968) Multifactorial inheritance hypothesis for the etiology of congenita heart diseases. The genetic-environmental interaction. Circulation 38: 604-617.

2. van der Bom T, Bouma BJ, Meijboom FJ, Zwinderman AH, Mulder BJ (2012) The prevalence of adult congenital heart disease, results from a systematic review and evidence based calculation. Am Heart J 164: 568-575.

3. Blalock A, Taussig HB (1984) Landmark article May 19, 1945: The surgical treatment of malformations of the heart in which there is pulmonary stenosis or pulmonary atresia. By Alfred Blalock and Helen B. Taussig. JAMA 251: 21232138.

4. de Leval MR, McKay R, Jones M, Stark J, Macartney FJ (1981) Modified Blalock-Taussig shunt. Use of subclavian artery orifice as flow regulator in prosthetic systemic-pulmonary artery shunts. J Thorac Cardiovasc Surg 81: 112-119.

5. Rao PS (2009) When and how should atrial septal defects be closed in adults? $\mathrm{J}$ Invasive Cardiol 21: 76-82.

6. Rao PS (2012) Why, when and how should atrial septal defects be closed in adults. In. Rao PS (Editor). Atrial Septal Defect, ISBN 978-953-51-0531-2; InTech, Rijeka, Croatia, April: 121-138.

7. Deanfield JE, McKenna WJ, Hallidie-Smith KA (1980) Detection of late arrhythmia and conduction disturbance after correction of tetralogy of Fallot Br Heart J 44: 248-253.

8. Gatzoulis MA, Till JA, Somerville J, Redington AN (1995) Mechanoelectrica interaction in tetralogy of Fallot. QRS prolongation relates to right ventricular 
Citation: Rao PS (2013) What an Adult Cardiologist Should Know about Cyanotic Congenital Heart Disease? J Cardiovasc Dis Diagn 1: 104. doi:10.4172/2329-9517.1000104

size and predicts malignant ventricular arrhythmias and sudden death Circulation 92: 231-237.

9. Silka MJ, Hardy BG, Menashe VD, Morris CD (1998) A population-based prospective evaluation of risk of sudden cardiac death after operation for common congenital heart defects. J Am Coll Cardiol 32: 245-251.

10. Gatzoulis MA, Balaji S, Webber SA, Siu SC, Hokanson JS, et al. (2000) Risk factors for arrhythmia and sudden cardiac death late after repair of tetralogy of Fallot: a multicentre study. Lancet 356: 975-981.

11. Nollert G, Fischlein T, Bouterwek S, Böhmer C, Klinner W, et al. (1997) Longterm survival in patients with repair of tetralogy of Fallot: 36-year follow-up of 490 survivors of the first year after surgical repair. J Am Coll Cardiol 30: 13741383.

12. Khairy P, Landzberg MJ, Gatzoulis MA, Lucron H, Lambert J, et al. (2004) Value of programmed ventricular stimulation after tetralogy of fallot repair: a multicenter study. Circulation 109: 1994-2000.

13. Roos-Hesselink J, Perlroth MG, McGhie J, Spitaels S (1995) Atrial arrhythmias in adults after repair of tetralogy of Fallot. Correlations with clinical, exercise, and echocardiographic findings. Circulation 91: 2214-2219.

14. Rao PS (2001) Stents in the management of congenital heart disease in pediatric and adult patients. Indian Heart J 53: 714-730.

15. Sahu R, Rao PS (2012) Transcatheter stent therapy in children: An update. Pediatr Therapeut; S5:001.

16. Rao PS (2007) Percutaneous balloon pulmonary valvuloplasty: state of the art Catheter Cardiovasc Interv 69: 747-763.

17. Rao PS (1993) Balloon dilatation of stenotic bioprosthetic valves. In: Rao (ed): Transcatheter Therapy in Pediatric Cardiology, Wiley-Liss, New York, NY: 255-

18. Powell AJ, Lock JE, Keane JF, Perry SB (1995) Prolongation of RV-PA conduit life span by percutaneous stent implantation. Intermediate-term results. Circulation 92: 3282-3288.

19. Bonhoeffer P, Boudjemline Y, Saliba Z, Merckx J, Aggoun Y, et al. (2000) Percutaneous replacement of pulmonary valve in a right-ventricle to pulmonaryartery prosthetic conduit with valve dysfunction. Lancet 356: 1403-1405.

20. Lurz P, Bonhoeffer P, Taylor AM (2009) Percutaneous pulmonary valve implantation: an update. Expert Rev Cardiovasc Ther 7: 823-833.

21. McElhinney DB, Hellenbrand WE, Zahn EM, Jones TK, Cheatham JP, et al. (2010) Short- and medium-term outcomes after transcatheter pulmonary valve placement in the expanded multicenter US melody valve trial. Circulation 122: 507-516.

22. Kenny D, Hijazi ZM, Kar S, Rhodes J, Mullen M, et al. (2011) Percutaneous implantation of the Edwards SAPIEN transcatheter heart valve for conduit failure in the pulmonary position: early phase 1 results from an international multicenter clinical trial. J Am Coll Cardiol 58: 2248-2256.

23. Rathi VK, Doyle M, Williams RB, Yamrozik J, Shannon RP, et al. (2005) Massive aortic aneurysm and dissection in repaired tetralogy of Fallot; diagnosis by cardiovascular magnetic resonance imaging. Int J Cardiol 101: 169-170.

24. Kim TS, Na CY, Baek JH, Yang JS (2011) Aortic root and ascending aortic aneurysm in an adult with a repaired tetralogy of fallot. Korean $\mathrm{J}$ Thorac Cardiovasc Surg 44: 292-293.

25. Rao PS (2010) Transposition of the great arteries in the neonate. Neonatology Today 5: 1-8

26. Senning A (1959) Surgical correction of transposition of the great vessels. Surgery 45: 966-980.

27. Mustard WT, Keith JD, Trusler GA, Fowler R, Kidd L (1964) The Surgical Management Of Transposition Of The Great Vessels. J Thorac Cardiovasc Surg 48: 953-958.

28. Mustard WT (1964) Successful Two-Stage Correction Of Transposition Of The Great Vessels. Surgery 55: 469-472.

29. Jatene AD, Fontes VF, Paulista PP, Souza LC, Neger F, et al. (1976) Anatomic correction of transposition of the great vessels. J Thorac Cardiovasc Surg 72 : 364-370.

30. Rastelli GC, Wallace RB, Ongley PA (1969) Complete repair of transposition of the great arteries with pulmonary stenosis. A review and report of a case corrected by using a new surgical technique. Circulation 39: 83-95.
31. Rastelli GC McGoon DC, Wallace RB (1969) Anatomic correction of transposition of the great arteries with ventricular septal defect and subpulmonary stenosis. J Thorac Cardiovasc Surg 58: 545-552.

32. Helbing WA, Hansen B, Ottenkamp J, Rohmer J, Chin JG, et al. (1994) Long-term results of atrial correction for transposition of the great arteries. Comparison of Mustard and Senning operations. J Thorac Cardiovasc Surg 108: 363-372.

33. Wilson NJ, Clarkson PM, Barratt-Boyes BG, Calder AL, Whitlock RM, et al. (1998) Long-term outcome after the mustard repair for simple transposition of the great arteries. 28-year follow-up. J Am Coll Cardiol 32: 758-765.

34. Kammeraad JA, van Deurzen $\mathrm{CH}$, Sreeram N, Bink-Boelkens MT, Ottenkamp $\mathrm{J}$, et al. (2004) Predictors of sudden cardiac death after Mustard or Senning repair for transposition of the great arteries. J Am Coll Cardiol 44: 1095-1102.

35. Rao PS, Thapar MK (1993) Balloon dilatation of other congenital and acquired stenotic lesions of the cardiovascular system. In: Rao PS (ed.). Transcatheter Therapy in Pediatric Cardiology, Wiley-Liss, New York, NY : 275-319.

36. Rao PS, Wilson AD (1992) Chylothorax, an unusual complication of baffle obstruction following Mustard operation: successful treatment with balloon angioplasty. Am Heart J 123: 244-248.

37. Daehnert I, Hennig B, Wiener M, Rotzsch C (2005) Interventions in leaks and obstructions of the interatrial baffle late after Mustard and Senning correction for transposition of the great arteries. Catheter Cardiovasc Interv 66: 400-407.

38. Hurwitz RA, Caldwell RL, Girod DA, Brown J (1996) Right ventricular systolic function in adolescents and young adults after Mustard operation for transposition of the great arteries. Am J Cardiol 77: 294-297.

39. Khairy P, Clair M, Fernandes SM, Blume ED, Powell AJ, et al. (2013) Cardiovascular outcomes after the arterial switch operation for D-transposition of the great arteries. Circulation 127: 331-339.

40. Michalak KW, Moll JA, Moll M, Dryzek P, Moszura T, et al. (2013) The neoaortic root in children with transposition of the great arteries after an arterial switch operation. Eur J Cardiothorac Surg.

41. Hutter PA, Kreb DL, Mantel SF, Hitchcock JF, Meijboom EJ, et al. (2002) Twenty-five years' experience with the arterial switch operation. J Thorac Cardiovasc Surg 124: 790-797.

42. Lev M, Saphir O (1942) Truncus arteriosus communis persistens. J Pediatr 20: 74-84.

43. Ebert PA, Turley K, Stanger P, Hoffman JI, Heymann MA, et al. (1984) Surgical treatment of truncus arteriosus in the first 6 months of life. Ann Surg 200: 451456

44. Lund AM, Vogel M, Marshall AC, Emani SM, Pigula FA, et al. (2011) Early reintervention on the pulmonary arteries and right ventricular outflow tract after neonatal or early infant repair of truncus arteriosus using homograft conduits. Am J Cardiol 108: 106-113.

45. Carlo WF, McKenzie ED, Slesnick TC (2011) Root dilation in patients with truncus arteriosus. Congenit Heart Dis 6: 228-233.

46. John S, Sukumar IP, Muralidharan S, Jairaj PS, Krishaswami S, et al. (1981) Total anomalous pulmonary venous return in children and adults. Results of corrective surgery. J Cardiovasc Surg (Torino) 22: 9-14.

47. Berg GA, Jamieson MP, Pollock JC (1986) Repair of total anomalous pulmonary venous connection in adults. Thorac Cardiovasc Surg 34: 359-361.

48. Joy J, Subramanyan R, Balakrishnan KG (1987) Total anomalous pulmonary venous connection (TAPVC) in children and adults: a pre and post operative study. Indian Heart J 39: 340-346.

49. Rodríguez-Collado J, Attie F, Zabal C, Troyo P, Olvera S, et al. (1992) Total anomalous pulmonary venous connection in adults. Long-term follow-up. J Thorac Cardiovasc Surg 103: 877-880.

50. Ashoush R, Jebara VA, el Rassi I, Badawi G, Sarkis A, et al. (1993) Tota anomalous pulmonary venous connection in adults--a surgical review. J Med Liban 41: 230-235.

51. Jian XH, Huang J, Ding Y, Xiao XJ, Wu M, et al. (2012) Surgical outcome of isolated total anomalous pulmonary venous connection in adults: a 14-year experience. J Card Surg 27: 736-739.

52. Rao PS (1982) Terminology: tricuspid atresia or univentricular heart? In Rao PS (ed.). Tricuspid Atresia, Mount Kisco, NY, Futura Publishing Co 3-6. 
Citation: Rao PS (2013) What an Adult Cardiologist Should Know about Cyanotic Congenital Heart Disease? J Cardiovasc Dis Diagn 1: 104. doi:10.4172/2329-9517.1000104

53. Rao PS (1980) A unified classification for tricuspid atresia. Am Heart J 99: 799-804

54. Rao PS, Sissman NJ (1971) Spontaneous closure of physiologically advantageous ventricular septal defects. Circulation 43: 83-90.

55. Rao PS, Linde LM, Liebman J, Perrin E (1974) Functional closure of physiologically advantageous ventricular septal defects. Observations in three cases with tricuspid atresia. Am J Dis Child 127: 36-40.

56. Rao PS (1977) Natural history of the ventricular septal defect in tricuspid atresia and its surgical implications. Br Heart J 39: 276-288.

57. Rao PS (1983) Further observations on the spontaneous closure of physiologically advantageous ventricular septal defects in tricuspid atresia: surgical implications. Ann Thorac Surg 35: 121-131.

58. Fontan F, Baudet E (1971) Surgical repair of tricuspid atresia. Thorax 26: 240248.

59. Kreutzer G, Bono H, Galindez E (1971) Una operacion para la correccion de la atresia tricuspidea. Ninth Argentinean Congress of Cardiology, Buenos Aires, Argentina, Oct. 31-Nov. 6.

60. de Leval MR, Kilner P, Gewillig M, Bull C (1988) Total cavopulmonary connection: a logical alternative to atriopulmonary connection for complex Fontan operations. Experimental studies and early clinical experience. $J$ Thorac Cardiovasc Surg 96: 682-695.

61. Norwood WI, Lang P, Casteneda AR, Campbell DN (1981) Experience with operations for hypoplastic left heart syndrome. J Thorac Cardiovasc Surg 82: 511-519.

62. Sano S, Ishino K, Kawada M, Arai S, Kasahara S, et al. (2003) Right ventriclepulmonary artery shunt in first-stage palliation of hypoplastic left heart syndrome. J Thorac Cardiovasc Surg 126: 504-509.

63. Kannankeril PJ, Anderson ME, Rottman JN, Wathen MS, Fish FA (2003) Frequency of late recurrence of intra-atrial reentry tachycardia after radiofrequency catheter ablation in patients with congenital heart disease. Am J Cardiol 92: 879-881.

64. Mavroudis C, Deal BJ, Backer CL (2002) The beneficial effects of tota cavopulmonary conversion and arrhythmia surgery for the failed Fontan. Semin Thorac Cardiovasc Surg Pediatr Card Surg Annu 5: 12-24.

65. Goff DA, Blume ED, Gauvreau K, Mayer JE, Lock JE, et al. (2000) Clinica outcome of fenestrated Fontan patients after closure: the first 10 years. Circulation 102: 2094-2099.

66. Balling G, Vogt M, Kaemmerer H, Eicken A, Meisner H, et al. (2000) Intracardiac thrombus formation after the Fontan operation. J Thorac Cardiovasc Surg 119: 745-752.

67. Varma C, Warr MR, Hendler AL, Paul NS, Webb GD, et al. (2003) Prevalence of "silent" pulmonary emboli in adults after the Fontan operation. J Am Coll Cardiol 41: 2252-2258.

68. Monagle P, Cochrane A, Roberts R, Manlhiot C, Weintraub R, et al. (2011) Fontan Anticoagulation Study Group. A multicenter, randomized trial comparing heparin/warfarin and acetylsalicylic acid as primary thromboprophylaxis for 2 years after the Fontan procedure in children. J Am Coll Cardiol 58: 645-651.
69. Chiu NT, Lee BF, Hwang SJ, Chang JM, Liu GC et al (2001) Proteinlosing enteropathy: diagnosis with $(99 \mathrm{~m})$ Tc-labeled human serum albumin scintigraphy. Radiology 219: 86-90.

70. Feldt RH, Driscoll DJ, Offord KP, Cha RH, Perrault J, et al. (1996) Proteinlosing enteropathy after the Fontan operation. J Thorac Cardiovasc Surg 112 672-680.

71. Giannico S, Hammad F, Amodeo A, Michielon G, Drago F, et al. (2006) Clinical outcome of 193 extracardiac Fontan patients: the first 15 years. J Am Coll Cardiol 47: 2065-2073.

72. Rao PS (2007) Protein-losing enteropathy following the Fontan operation. J Invasive Cardiol 19: 447-448.

73. Masetti P, Marianeschi SM, Cipriani A, lorio FS, Marcelletti CF (1999) Reversa of protein-losing enteropathy after ligation of systemic-pulmonary shunt. Ann Thorac Surg 67: 235-236.

74. Mertens L, Dumoulin M, Gewillig M (1994) Effect of percutaneous fenestration of the atrial septum on protein-losing enteropathy after the Fontan operation. Br Heart J 72: 591-592.

75. Lemes V, Murphy AM, Osterman FA, Laschinger JC, Kan JS (1998) Fenestration of extracardiac fontan and reversal of protein-losing enteropathy: case report. Pediatr Cardiol 19: 355-357.

76. Kreutzer J, Keane JF, Lock JE, Walsh EP, Jonas RA, et al. (1996) Conversion of modified Fontan procedure to lateral atrial tunnel cavopulmonary anastomosis. J Thorac Cardiovasc Surg 111: 1169-1176.

77. Marcelletti CF, Hanley FL, Mavroudis C, McElhinney DB, Abella RF, et al. (2000) Revision of previous Fontan connections to total extracardiac cavopulmonary anastomosis: A multicenter experience. J Thorac Cardiovasc Surg 119: 340-346.

78. Lopez JA (2007) Transvenous right atrial and left ventricular pacing after the Fontan operation: long-term hemodynamic and electrophysiologic benefit of early atrioventricular resynchronization. Tex Heart Inst J 34: 98-101.

79. Estner HL, Kolb C, Schmitt C, Deisenhofer I, Pflaumer A, et al. (2008) Longterm transvenous AV-sequential pacing in a failing atriopulmonary Fontan patient. Int J Cardiol 127: e93-95.

80. Brancaccio G, Carotti A, D'Argenio P, Michielon G, Parisi F (2003) Proteinlosing enteropathy after Fontan surgery: resolution after cardiac transplantation. $\mathrm{J}$ Heart Lung Transplant 22: 484-486.

81. Sheikh AM, Tang AT, Roman K, Baig K, Mehta R, et al. (2004) The failing Fontan circulation: successful conversion of atriopulmonary connections. $J$ Thorac Cardiovasc Surg 128: 60-66.

82. Gamba A, Merlo M, Fiocchi R, Terzi A, Mammana C, et al. (2004) Heart transplantation in patients with previous Fontan operations. J Thorac Cardiovasc Surg 127: 555-562.

83. Jayakumar KA, Addonizio LJ, Kichuk-Chrisant MR, Galantowicz ME, Lamou JM, et al. (2004) Cardiac transplantation after the Fontan or Glenn procedure. J Am Coll Cardiol 44: 2065-2072. 